Supporting Information for Environmental Science \& Technology

\title{
Enhanced Microbial Ferrihydrite Reduction by Pyrogenic Carbon: Impact of Graphitic Structures
}

\author{
Wentao $\mathrm{Yu}^{1,2}$, Chiheng $\mathrm{Chu}^{1,2}$, Baoliang Chen ${ }^{1,2, *}$ \\ ${ }^{1}$ Department of Environmental Science, Zhejiang University, Hangzhou 310058, China; \\ ${ }^{2}$ Zhejiang Provincial Key Laboratory of Organic Pollution Process and Control, Hangzhou \\ 310058, China \\ * Corresponding Author Email: blchen@zju.edu.cn
}

Supporting information consists of 29 pages, including 4 Supplemental materials, 4 Tables and 19 Figures. 
Text S1. Chemicals Used in the Study.

Iron nitrate nonahydrate, potassium hydroxide, ammonium acetate, acetate, hydroxylammonium chloride, graphite, 1,4-Piperazinediethanesulfonic acid (PIPES) and 2,2'-azino-bis(3-ethylbenzothiazoline-6-sulfonic acid) diammonium salt (ABTS) were purchased from Aladdin (Shanghai, China). Humic acids (from plants, $\mathrm{C}_{9} \mathrm{H}_{9} \mathrm{NO}_{6}$, HA) was purchased from J\&K (Beijing, China). 1,10-Phenanthroline was obtained from Sigma-Aldrich (St Louis, USA). Tryptone and yeast extract were obtained from Oxoid (Hants, UK). Zwitterionic viologen 4,4'-bipyridinium-1,1'-bis(2-ethylsulfonate) (ZiV) was synthesized as described previously. ${ }^{1}$ All chemicals were of analytical grade. Deionized water (18.2 M $\Omega \cdot \mathrm{cm}$, Milli-Q, Millipore) was used for preparing solution.

Text S2. Microbial Ferrihydrite Reduction in the Presence of PC Leachate.

PC leachate was prepared by mixing PC ( $5 \mathrm{~g} / \mathrm{L})$ with sterile, oxygen-free PIPES buffer (30 mM, pH 7.0) and shaken at $100 \mathrm{rpm}$ for $48 \mathrm{~h}$ in an anaerobic chamber. The PC suspensions were filtered through $0.22 \mu \mathrm{m}$ filters and the filtrates were referred to as PC leachate. Microbial ferrihydrite reduction in the presence of PC leachate was conducted with the same procedures as Microbial Ferrihydrite Reduction in the MATERIALS AND METHODS.

Text S3. Microbial Ferrihydrite Reduction in the Presence of Inorganic Minerals of PC. Inorganic minerals of PC were produced by pyrolysis of rice straw at different pyrolysis temperatures $\left(500,600,700,800\right.$, and $\left.900{ }^{\circ} \mathrm{C}\right)$ for $4 \mathrm{~h}$ under air. The obtained ash was 
washed using deionized water for three times. Inorganic minerals accounted for about $40 \mathrm{wt} \%$ of PC (Table S1), thus $2 \mathrm{~g} / \mathrm{L}$ inorganic minerals were added to medium, other conditions were same with Microbial Ferrihydrite Reduction in the MATERIALS AND METHODS.

Text S4. Microbial Ferrihydrite Reduction in the Absence of PC for Characterizing Mineralogical Changes of Ferrihydrite.

Five parallel experiments of microbial ferrihydrite reduction in the absence of PC were set up, and the conditions were same with Microbial Ferrihydrite Reduction in the MATERIALS AND METHODS. At designated time, one sample was sacrificed to characterize mineralogical changes of ferrihydrite using XRD and SEM. 
Table S1. Elemental composition (mass \%) and aromaticity index (AI) of PC RS500RS900.

\begin{tabular}{|c|c|c|c|c|c|}
\hline \multirow{2}{*}{$\mathbf{P C}$} & \multicolumn{4}{|c|}{ Contents (\%) } & \multirow{2}{*}{$\mathbf{A I}^{\mathrm{a}}$} \\
\hline & $\mathbf{C}$ & $\mathbf{H}$ & $\mathbf{O}$ & $\mathbf{N}$ & \\
\hline RS500 & 47.68 & 1.96 & 9.47 & 1.25 & 1.034 \\
\hline RS600 & 48.32 & 1.31 & 8.33 & 1.14 & 1.038 \\
\hline RS700 & 49.48 & 0.87 & 8.44 & 1.20 & 1.044 \\
\hline RS 800 & 49.02 & 0.87 & 8.41 & 1.14 & 1.043 \\
\hline RS900 & 49.42 & 0.75 & 7.77 & 1.07 & 1.042 \\
\hline
\end{tabular}

a AI refers to the ratio of $(1+[\mathrm{C}]-[\mathrm{O}]-0.5[\mathrm{H}]) /([\mathrm{C}]-[\mathrm{O}]-[\mathrm{N}])$. 
Table S2. Surface O/C ratios by XPS, C-C and C-O band percentages by deconvolution of C 1s XPS spectra of PC RS500-RS900.

\begin{tabular}{ccccc}
\hline PC & $\mathbf{O} / \mathbf{C}^{\mathbf{a}}$ & $\mathbf{C}-\mathbf{C} / \mathbf{C}=\mathbf{C}$ & $\mathbf{C}-\mathbf{O}$ & $\mathbf{C}=\mathbf{O}$ \\
\hline RS500 & 0.38 & 0.54 & 0.40 & 0.05 \\
RS600 & 0.33 & 0.55 & 0.35 & 0.10 \\
RS700 & 0.31 & 0.56 & 0.31 & 0.13 \\
RS800 & 0.29 & 0.62 & 0.23 & 0.15 \\
RS900 & 0.28 & 0.67 & 0.22 & 0.11 \\
\hline
\end{tabular}

a The ratio of $\mathrm{O} / \mathrm{C}$ was calculated according to the peak areas of $\mathrm{C} 1 \mathrm{~s}$ and $\mathrm{O} 1 \mathrm{~s}$. 
Table S3. EAC and EDC values of PC RS500-RS900 and rRS500-rRS900.

\begin{tabular}{|c|c|c|}
\hline $\mathbf{P C}$ & $\operatorname{EAC}\left(\mathrm{mmol} \mathrm{e}^{-}\left(\mathrm{g} \mathrm{PC}^{-1}\right)\right.$ & $\operatorname{EDC}\left(\mathrm{mmol} \mathrm{e}^{-}\left(\mathrm{g} \mathrm{PC}^{-1}\right)\right.$ \\
\hline RS500 & $0.62 \pm 0.02$ & $0.15 \pm 0.01$ \\
\hline RS600 & $0.67 \pm 0.01$ & $0.15 \pm 0.02$ \\
\hline RS700 & $1.08 \pm 0.01$ & $0.14 \pm 0.01$ \\
\hline RS800 & $0.91 \pm 0.07$ & $0.10 \pm 0.01$ \\
\hline RS900 & $0.77 \pm 0.07$ & $0.06 \pm 0.01$ \\
\hline rRS500 & $0.10 \pm 0.01$ & $0.15 \pm 0.01$ \\
\hline rRS600 & $0.12 \pm 0.01$ & $0.17 \pm 0.01$ \\
\hline rRS700 & $0.14 \pm 0.01$ & $0.16 \pm 0.02$ \\
\hline rRS800 & $0.17 \pm 0.01$ & $0.13 \pm 0.01$ \\
\hline rRS900 & $0.16 \pm 0.01$ & $0.08 \pm 0.01$ \\
\hline
\end{tabular}


Table S4. Reduction extents and initial reduction rates of $10 \mathrm{mM}$ ferrihydrite over 7 days in the presence of $5 \mathrm{~g} / \mathrm{L} \mathrm{PC}$.

\begin{tabular}{|c|c|c|c|}
\hline \multirow{3}{*}{ Group } & \multicolumn{2}{|c|}{ Reduction extent (\%) } & \multirow{3}{*}{$\begin{array}{l}\text { Reduction rate } \\
\qquad(\mathrm{Mm} / \mathrm{d})^{\mathrm{c}, \mathrm{d}}\end{array}$} \\
\hline & Chemical & Microbial & \\
\hline & reduction $^{a}$ & reduction ${ }^{b}$ & \\
\hline Control & I & 33.6 & $0.50 \pm 0.03$ \\
\hline RS500 & 12.5 & 27.7 & $0.60 \pm 0.07$ \\
\hline RS600 & 8.0 & 42.2 & $0.80 \pm 0.10$ \\
\hline RS700 & 9.8 & 46.7 & $0.98 \pm 0.10$ \\
\hline RS800 & 3.5 & 49.5 & $1.03 \pm 0.10$ \\
\hline RS900 & 3.2 & 51.2 & $1.07 \pm 0.02$ \\
\hline rRS500 & 20.2 & 21.0 & $0.24 \pm 0.03$ \\
\hline rRS600 & 19.4 & 23.7 & $0.42 \pm 0.05$ \\
\hline rRS700 & 18.5 & 35.3 & $0.83 \pm 0.08$ \\
\hline rRS800 & 15.8 & 40.5 & $0.85 \pm 0.10$ \\
\hline rRS900 & 13.4 & 40.6 & $0.88 \pm 0.07$ \\
\hline
\end{tabular}

${ }^{\text {a }}$ The fraction of ferrihydrite reduction by PC in the absence of $S$. oneidensis MR-1.

$\mathrm{b}$ The fraction of ferrihydrite reduction after deducting chemical reduction.

${ }^{\mathrm{c}}$ The initial rate constants were calculated using pseudo-zero-order model for the data sets for the first 3 days. ${ }^{2,3}$

$\mathrm{d}$ The uncertainties indicate standard deviation of triplicate samples. 


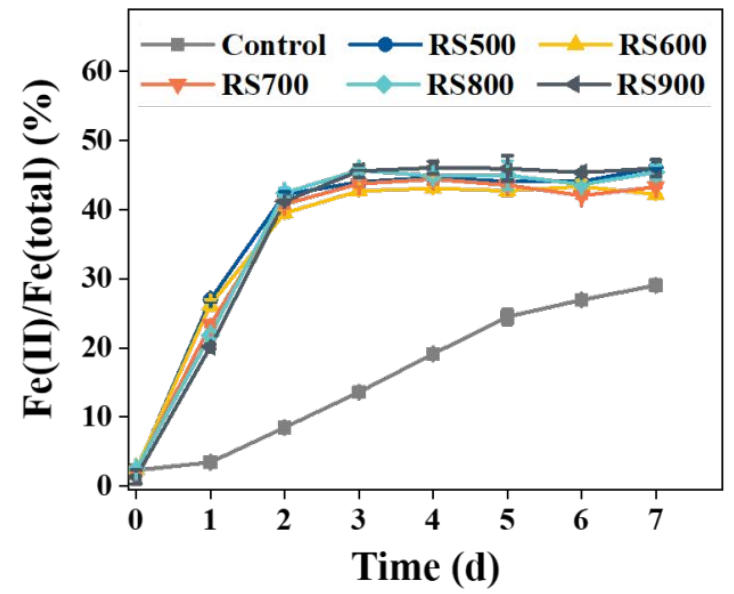

Figure S1. Ratios of $\mathrm{Fe}$ ( I ) $/ \mathrm{Fe}$ (total) during microbial reduction of $10 \mathrm{mM}$ ferrihydrite in the presence of PC leachate. RS500-RS900 represented the PC leachate obtained from the PC prepared at $500-900{ }^{\circ} \mathrm{C}$, respectively. 

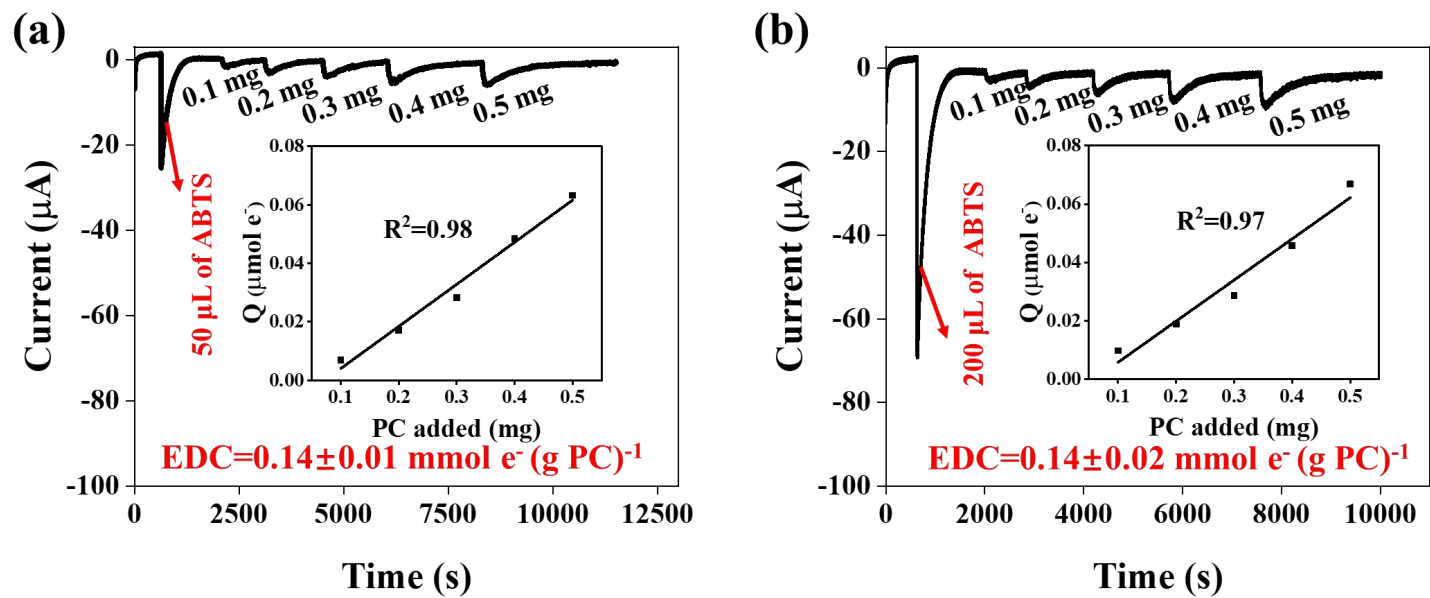

Figure S2. Oxidative current responses to increasing amounts of PC RS700 measured by mediated electrochemical oxidation $\left(\mathrm{MEO} ; E_{\mathrm{h}}=+0.61 \mathrm{~V}, \mathrm{pH} 7.0\right)$ in the presence of (a) $50 \mu \mathrm{L}$ of $10 \mathrm{mM}$ ABTS and (b) $200 \mu \mathrm{L}$ of $10 \mathrm{mM}$ ABTS. The numbers above the current peaks represent the mass of PC added into the cell. Integration of the current peaks yielded the numbers of electrons transferred from the PC, Q ( $\mu$ mol e-). Q increased linearly with increasing masses of PC (inserts). The slopes of linear regression lines of Q versus PC masses corresponded to the electron donating capacities of PC (EDC). 
(a)

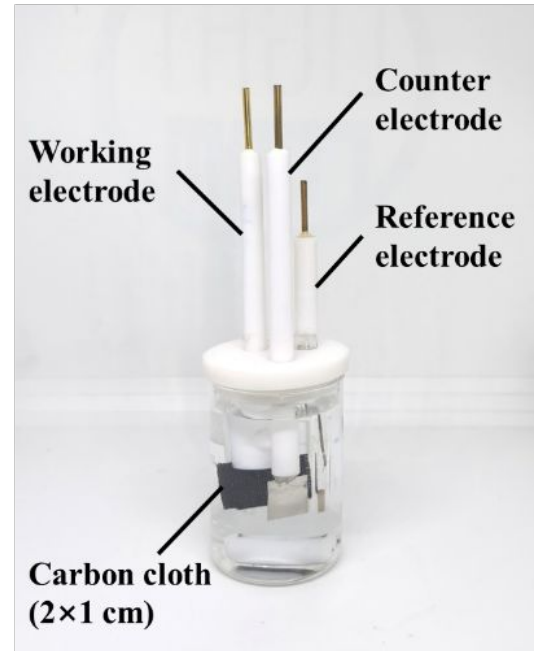

(b)

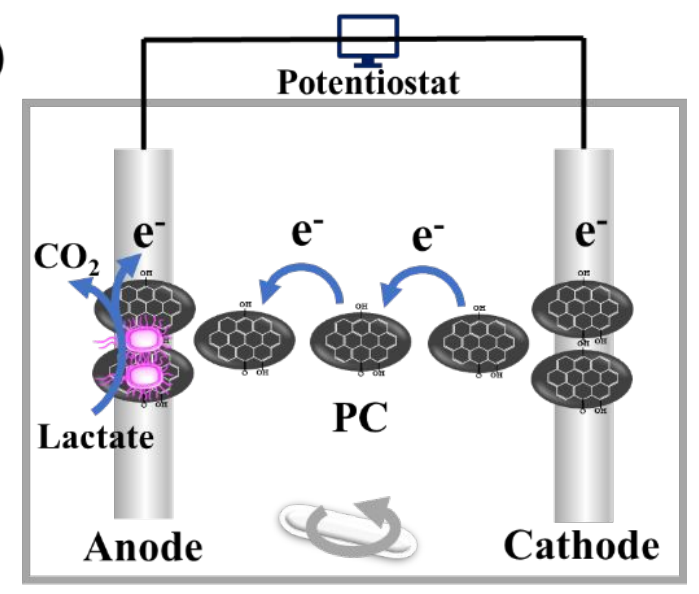

Microbial Electrolysis Cell

Figure S3. (a) Images of microbial electrolysis cell (MEC). (b) Schematic diagram of PC mediating extracellular electron transfer in MEC. 
(a)

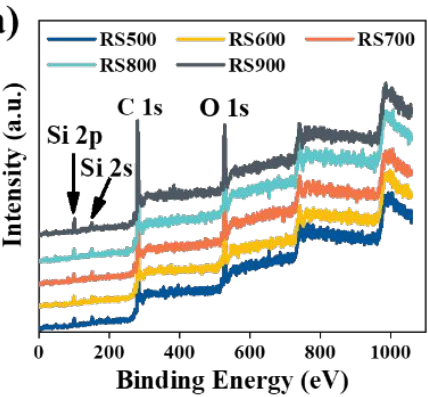

(d)

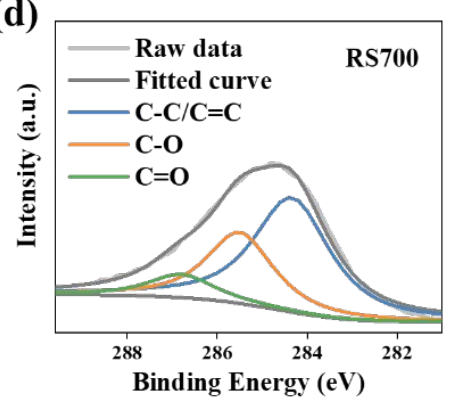

(b)

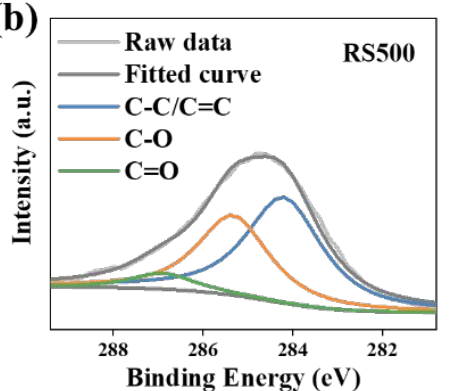

(e)

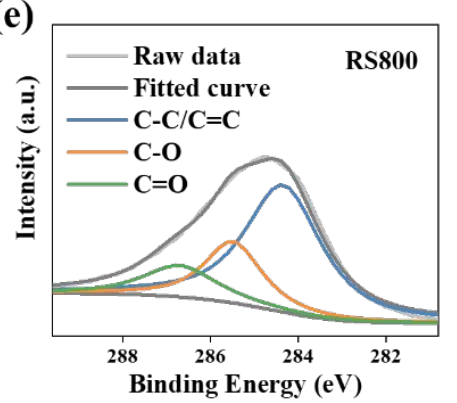

(c)

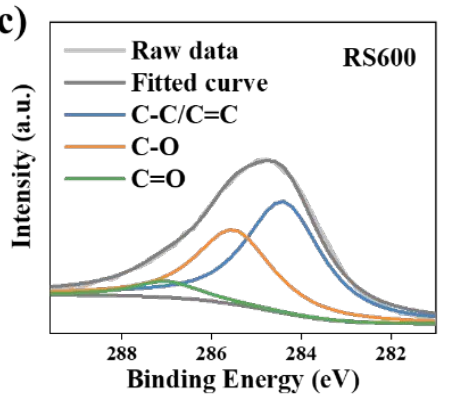

(f)

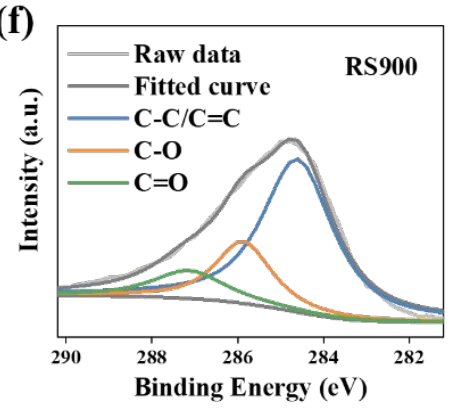

Figure S4. (a) XPS spectra and (b f) C 1s XPS spectra of PC RS500-RS900. C 1s XPS spectra was deconvoluted into three peaks at $284.4 \mathrm{eV}$ for $\mathrm{C}-\mathrm{C} / \mathrm{C}=\mathrm{C}$, at $286.0 \mathrm{eV}$ for $\mathrm{C}-\mathrm{O}$, and at $287.8 \mathrm{eV}$ for $\mathrm{C}=\mathrm{O}$. 


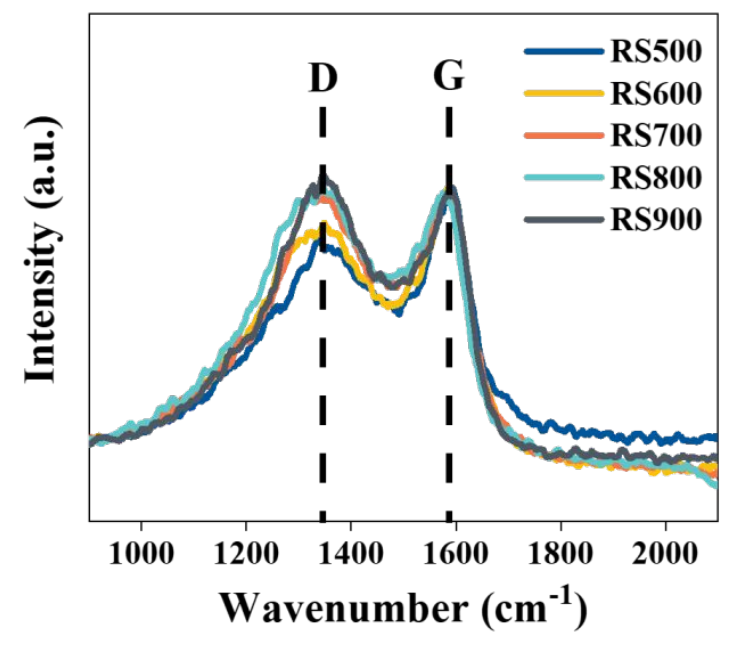

Figure S5. Raman spectra of PC RS500-RS900. The D peak $\left(1346 \mathrm{~cm}^{-1}\right)$ and the G peak $\left(1587 \mathrm{~cm}^{-1}\right)$ were assigned to the defects in aromatic structures and the $s p^{2}$ carbon, respectively. 

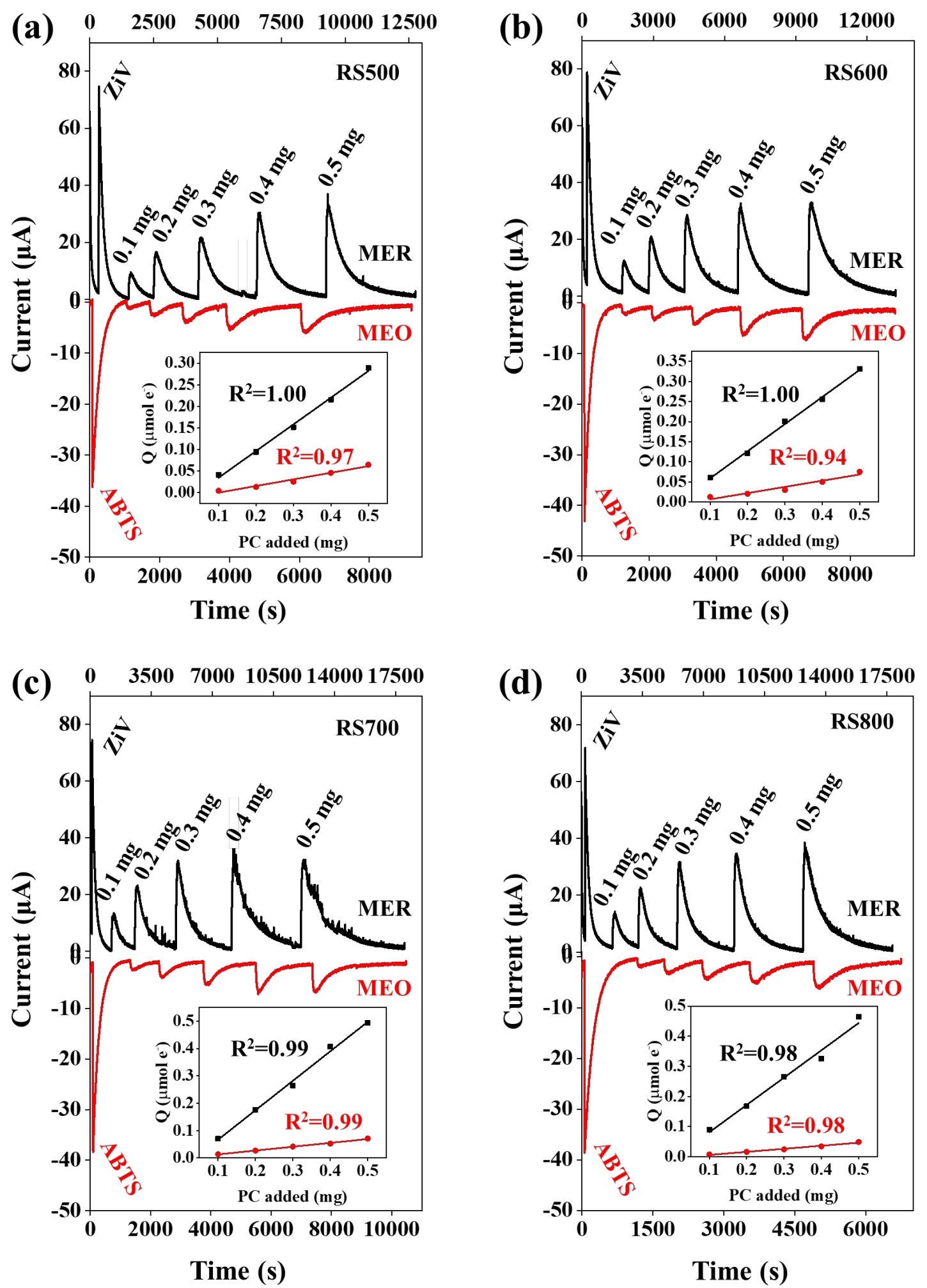


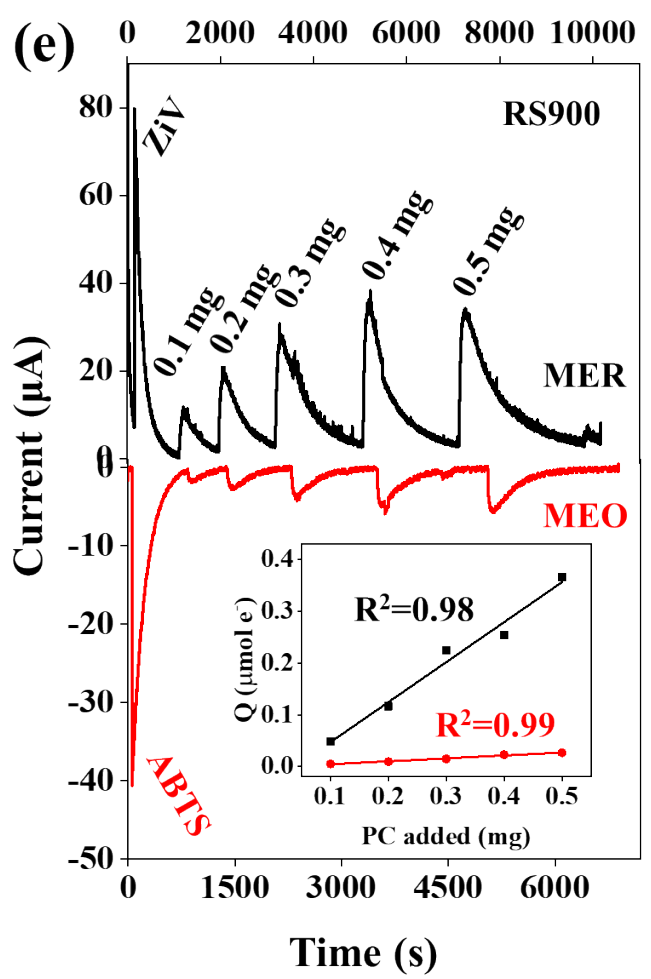

Figure S6. (a e) Reductive and oxidative current responses to increasing amounts of PC RS500-RS900 measured by mediated electrochemical reduction (MER; $E_{\mathrm{h}}=-0.49$ $\mathrm{V}, \mathrm{pH} 7.0$; black traces) and mediated electrochemical oxidation $\left(\mathrm{MEO} ; E_{\mathrm{h}}=+0.61 \mathrm{~V}\right.$, $\mathrm{pH}$ 7.0; red traces), respectively. The numbers above the current peaks represent the mass of PC added into the cell. Integration of the current peaks yielded the numbers of electrons transferred to and from the PC, Q ( $\mu$ mol e-). Q increased linearly with increasing masses of PC (inserts). The slopes of linear regression lines of Q versus PC masses corresponded to the electron accepting and donating capacities of PC (EAC and EDC). 


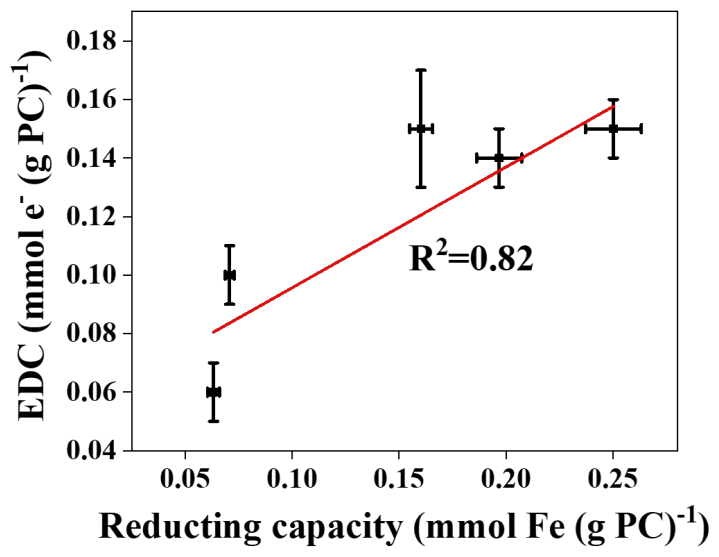

Figure S7. Correlation between EDC and reducing capacity for ferrihydrite of PC RS500-RS900. 


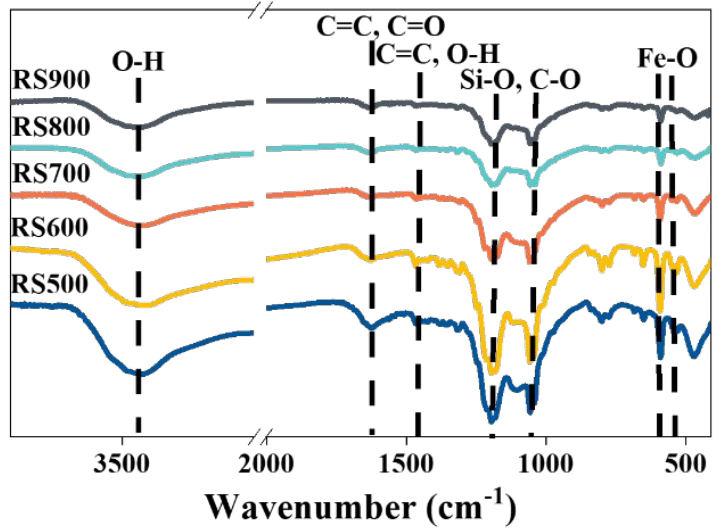

Figure S8. FTIR spectra of PC RS500-RS900 after reaction with ferrihydrite. 


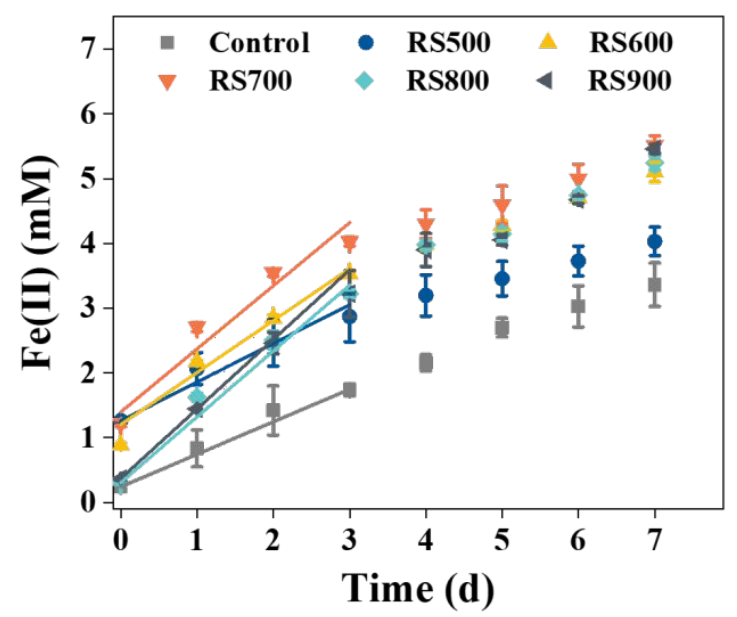

Figure S9. Pseudo-zero-order kinetic fittings of microbial reduction of $10 \mathrm{mM}$ ferrihydrite in the presence of $5 \mathrm{~g} / \mathrm{L}$ PC RS500-RS900 over first 3 days. 


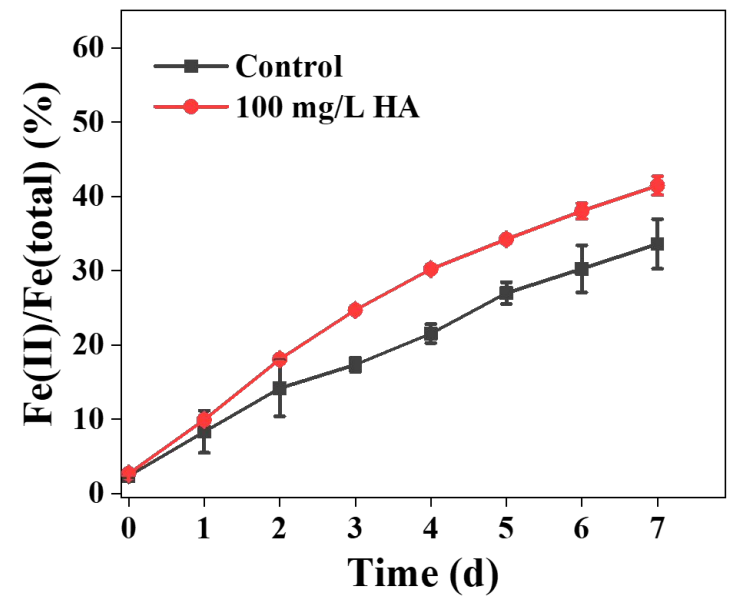

Figure S10. Ratios of $\mathrm{Fe}(\mathbb{I}) / \mathrm{Fe}($ total $)$ during microbial reduction of $10 \mathrm{mM}$ ferrihydrite in the presence of $100 \mathrm{mg} / \mathrm{L} \mathrm{HA}$. 
(a)
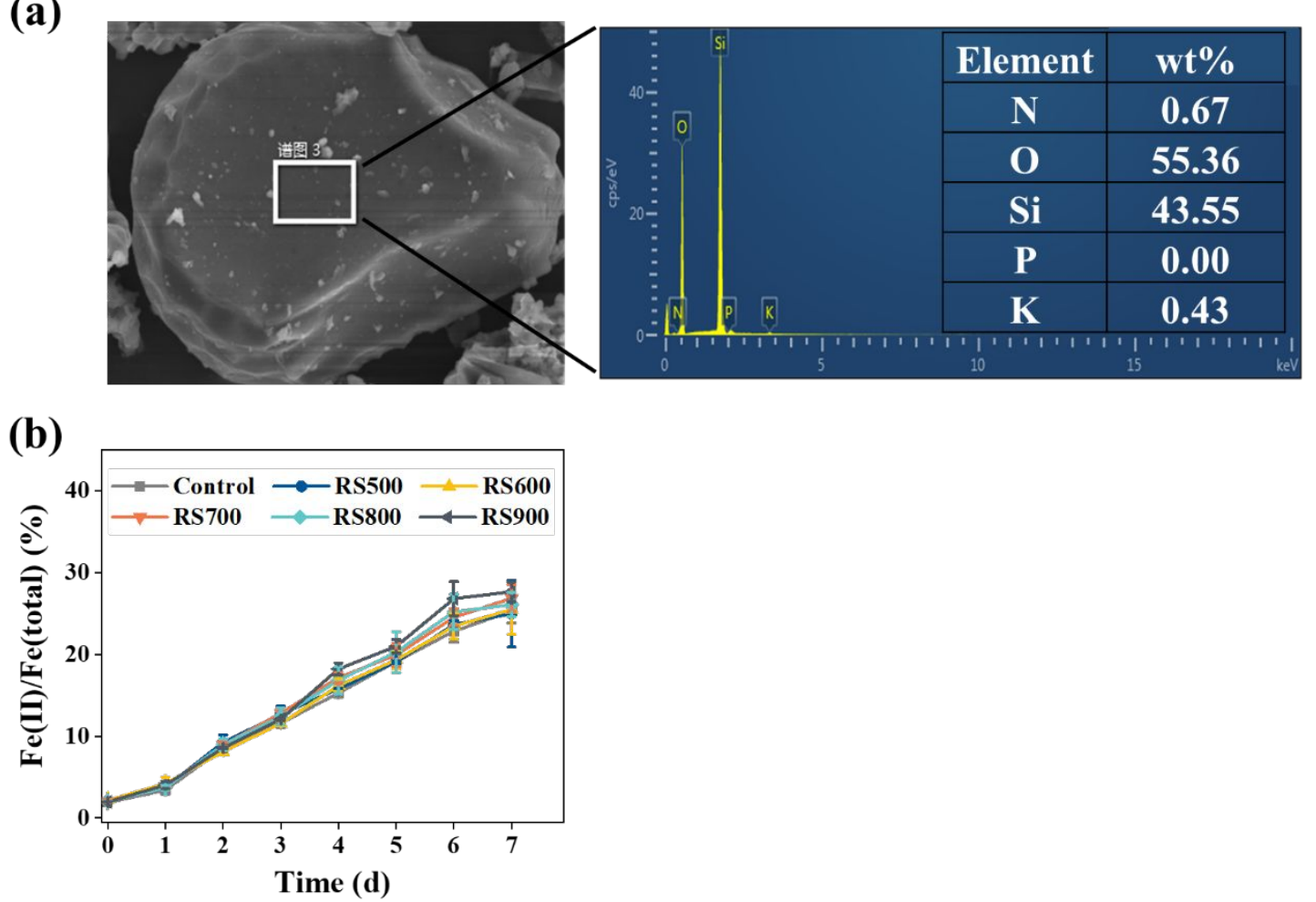

Figure S11. (a) SEM-EDS of inorganic minerals of RS700. (b) Ratios of $\mathrm{Fe}(\mathrm{II}) / \mathrm{Fe}$ (total) during microbial reduction of $10 \mathrm{mM}$ ferrihydrite in the presence of 2 g/L inorganic minerals of PC. RS500-RS900 represented the inorganic minerals prepared at $500-900{ }^{\circ} \mathrm{C}$, respectively. 

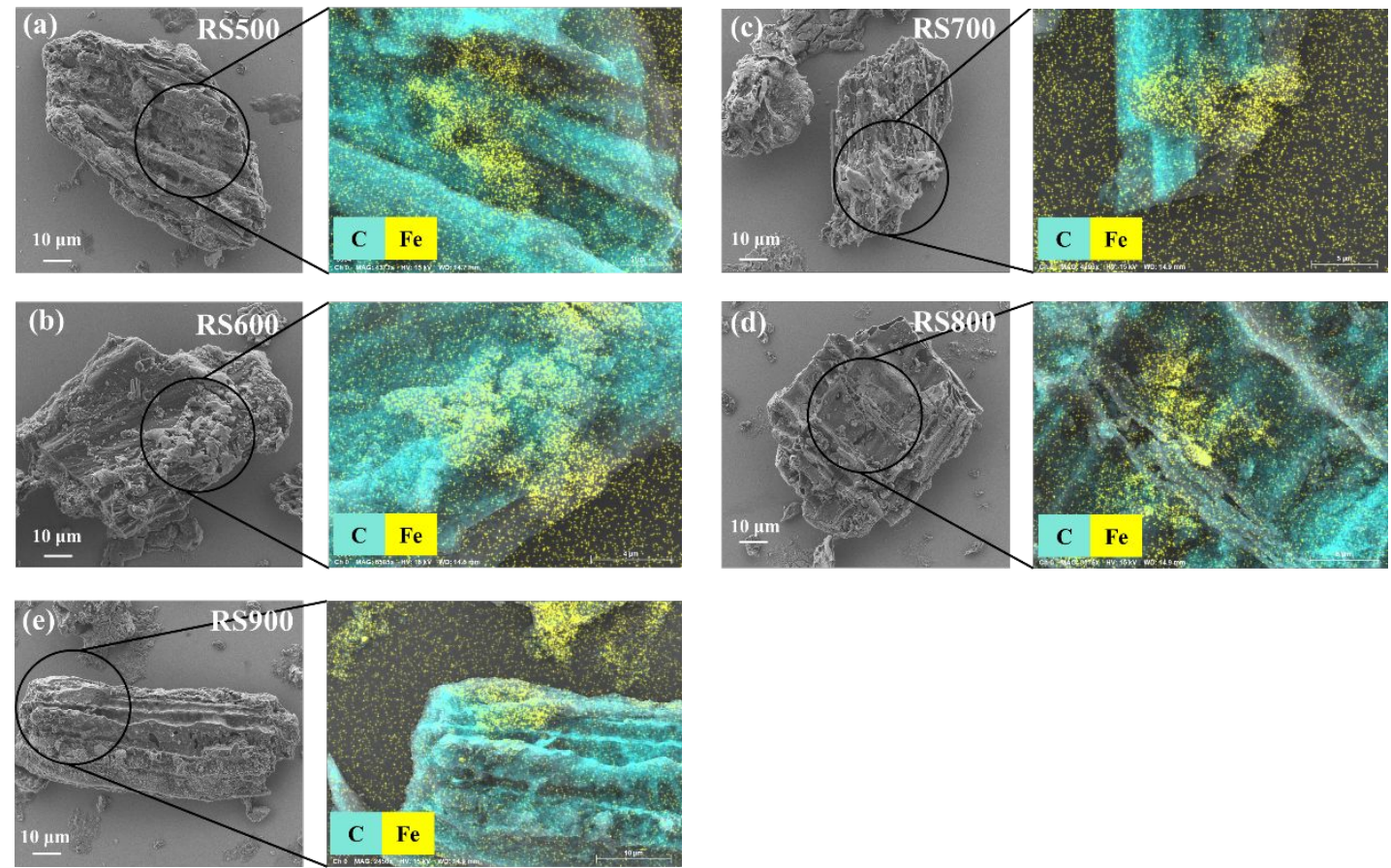

Figure S12. SEM-EDS images of Fe minerals produced by microbial reduction of 10 $\mathrm{mM}$ ferrihydrite after 7 days in the presence of $5 \mathrm{~g} / \mathrm{L}$ PC (a) RS500, (b) RS600, (c) RS700, (d) RS800, and (e) RS900. 


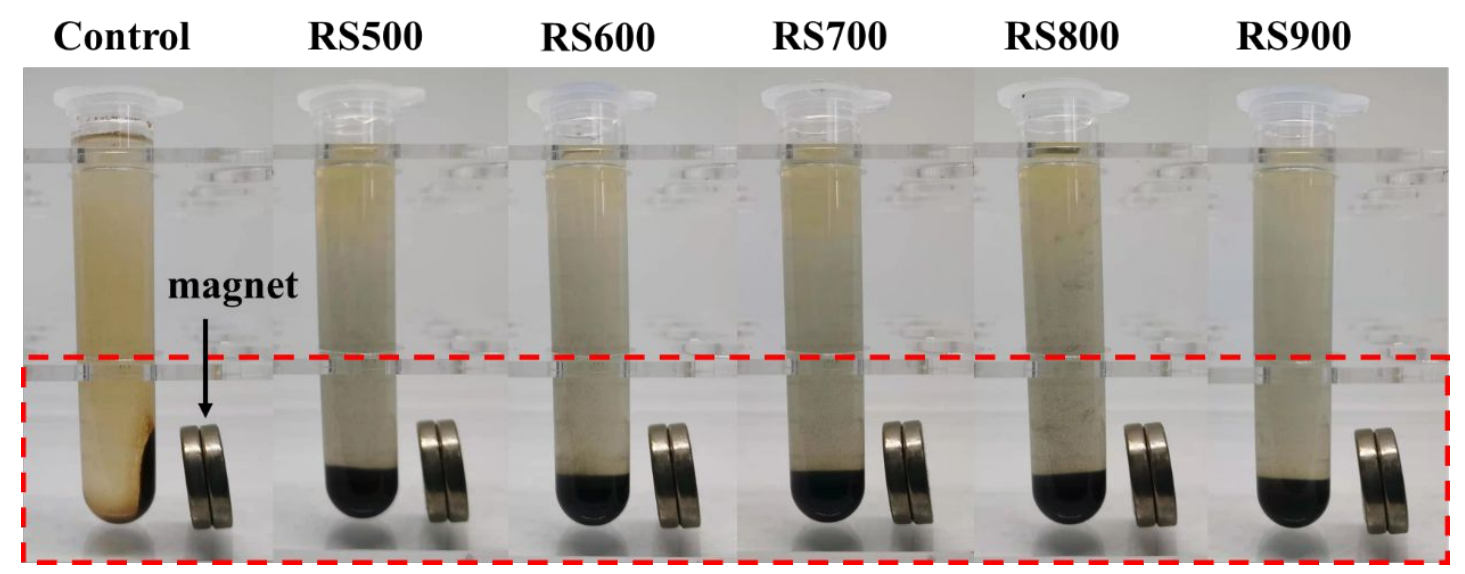

Figure S13. Magnetism of Fe minerals produced by microbial reduction of $10 \mathrm{mM}$ ferrihydrite in the absence and presence of $5 \mathrm{~g} / \mathrm{L}$ PC RS500-RS900 after 7 days. 

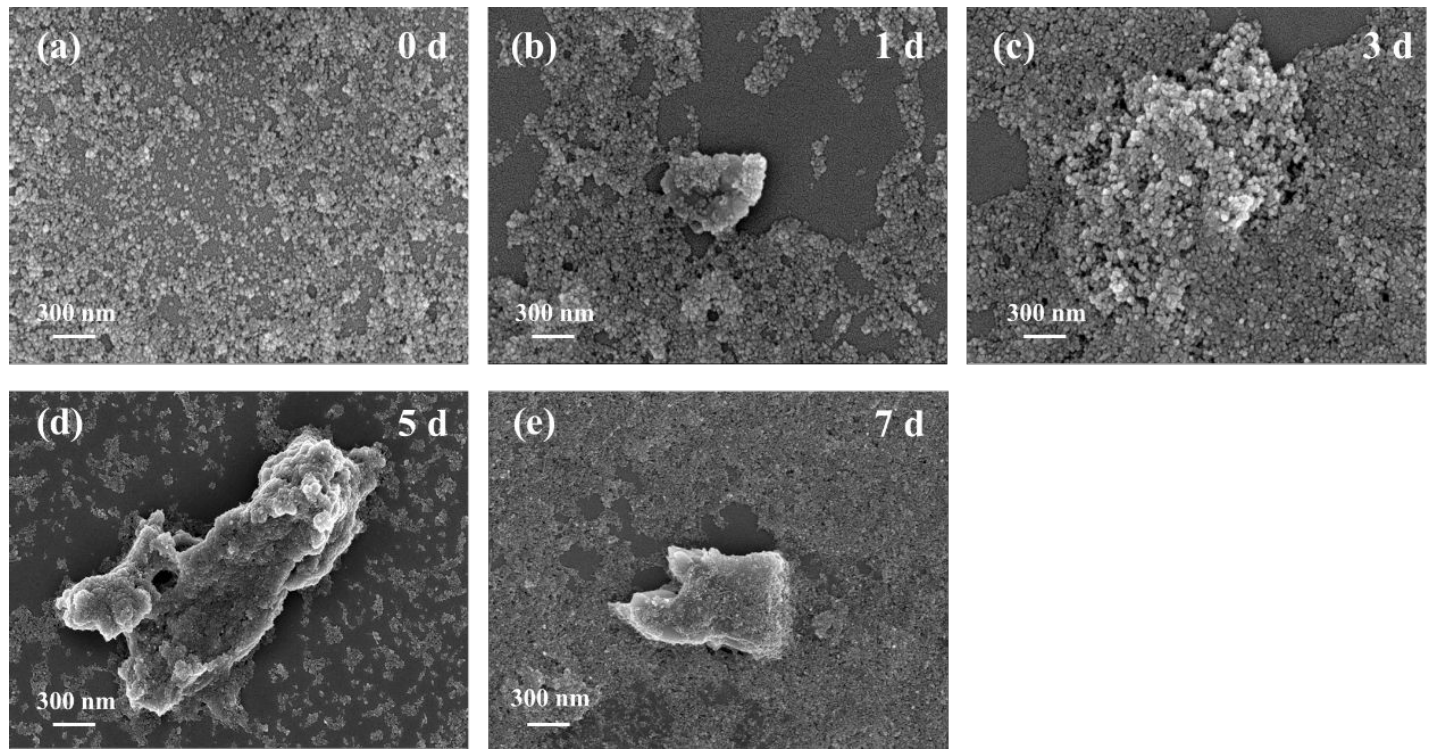

Figure S14. SEM images of Fe minerals produced by microbial reduction of $10 \mathrm{mM}$ ferrihydrite in the absence of PC after (a) $0 \mathrm{~d}$, (b) $1 \mathrm{~d}$, (c) $3 \mathrm{~d}$, (d) $5 \mathrm{~d}$, and (e) $7 \mathrm{~d}$. 
(a)

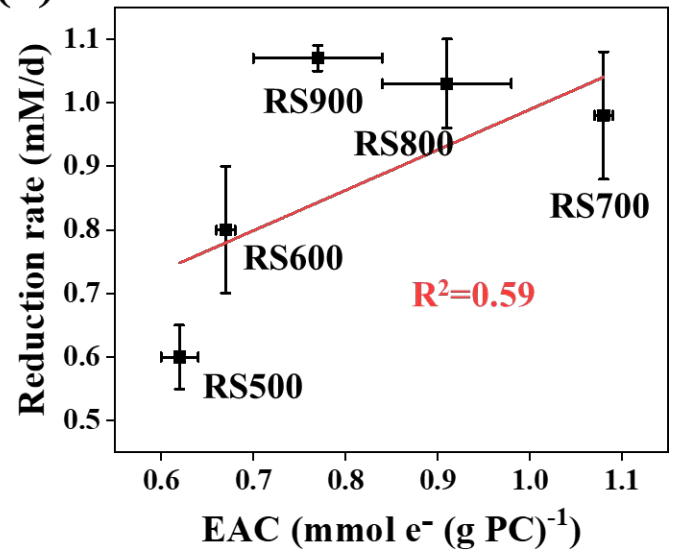

(c)

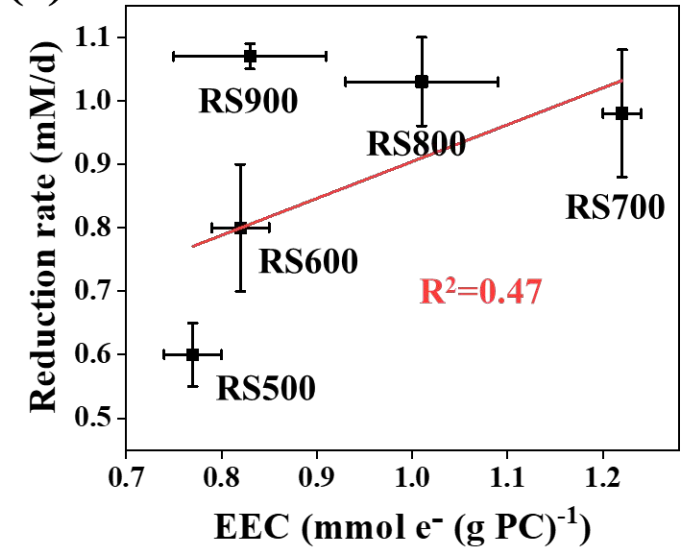

(b)

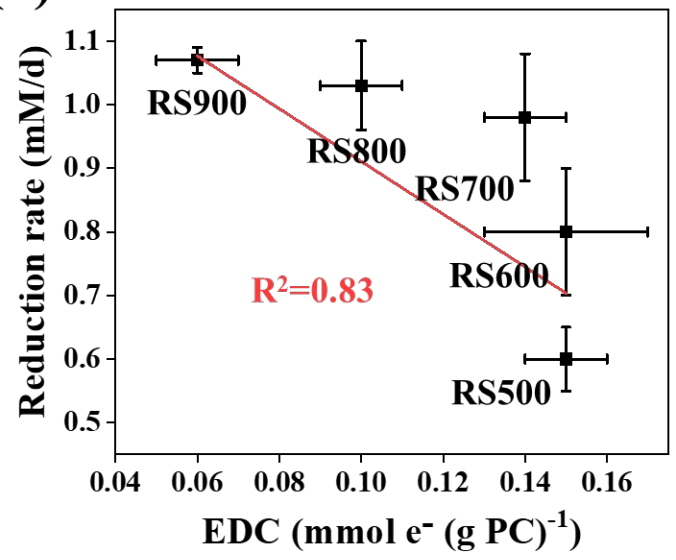

(d)

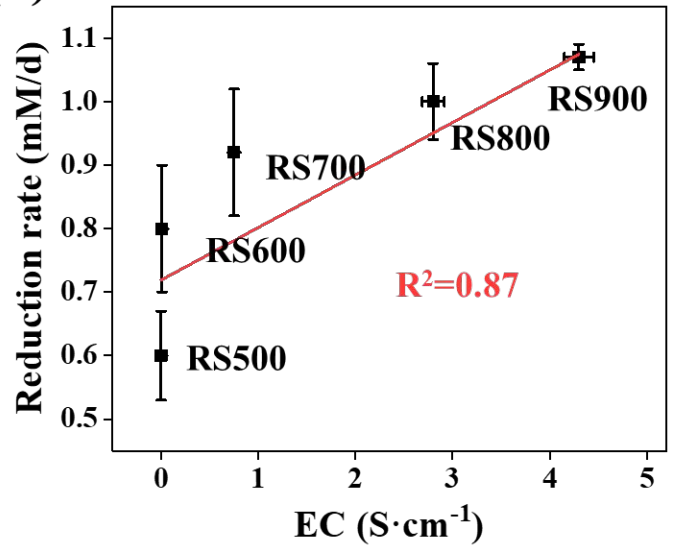

Figure S15. Correlation of reduction rate of ferrihydrite with (a) EAC, (b) EDC, (c) EEC and (d) EC of PC. 

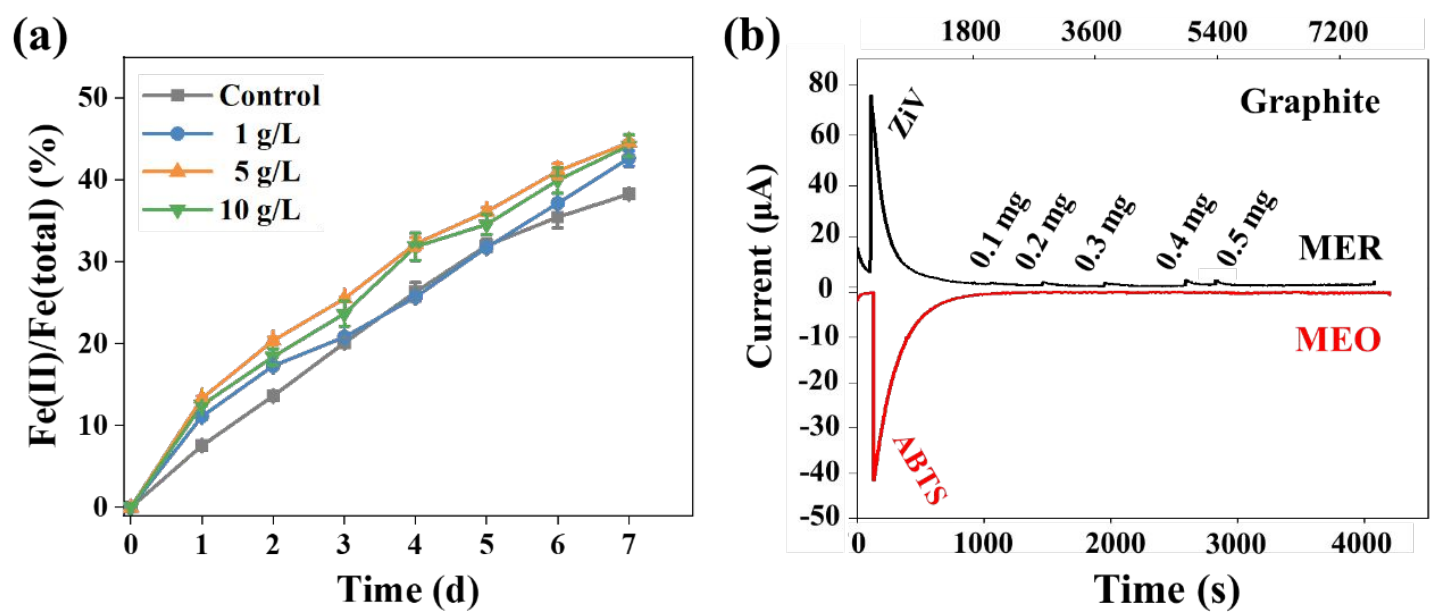

Figure S16. (a) Ratios of $\mathrm{Fe}(\mathbb{I}) / \mathrm{Fe}$ (total) during microbial reduction of $10 \mathrm{mM}$ ferrihydrite in the presence of pure graphite at a concentration of $1,5,10 \mathrm{~g} / \mathrm{L}$. (b) Reductive and oxidative current responses to increasing amounts of graphite measured by mediated electrochemical reduction (MER; $E_{\mathrm{h}}=-0.49 \mathrm{~V}, \mathrm{pH} 7.0$; black traces) and mediated electrochemical oxidation $\left(\mathrm{MEO} ; E_{\mathrm{h}}=+0.61 \mathrm{~V}, \mathrm{pH} 7.0\right.$; red traces), respectively. The numbers above the current peaks represent the mass of graphite added into the cell. 
(a)

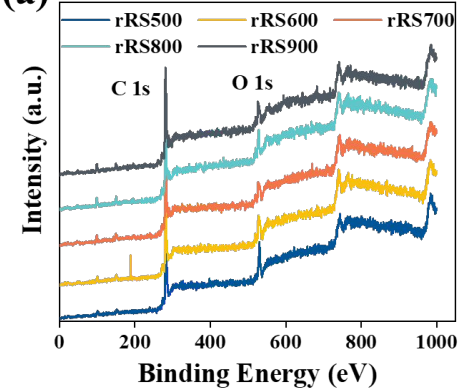

(d)

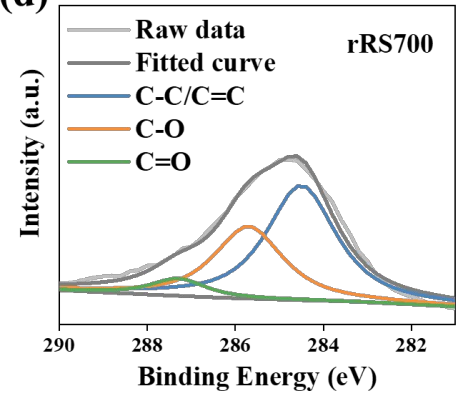

(b)

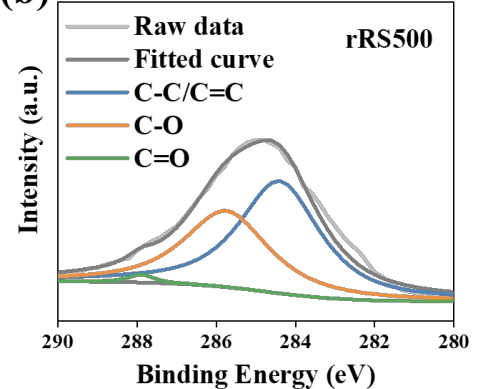

(e)

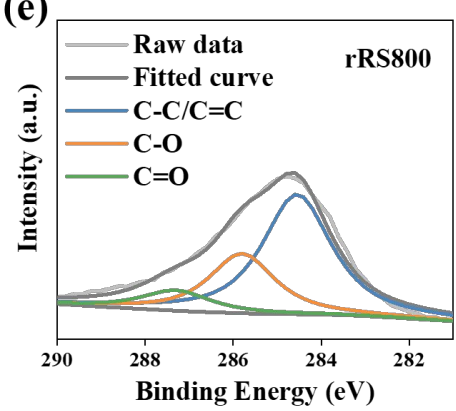

(c)

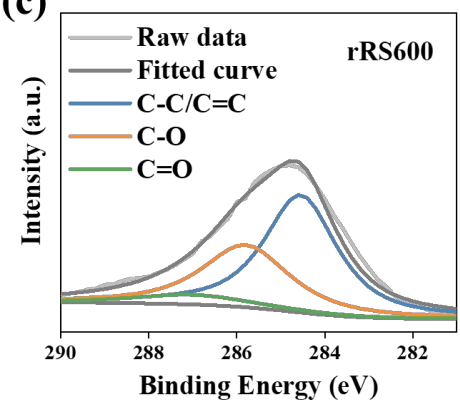

(f)

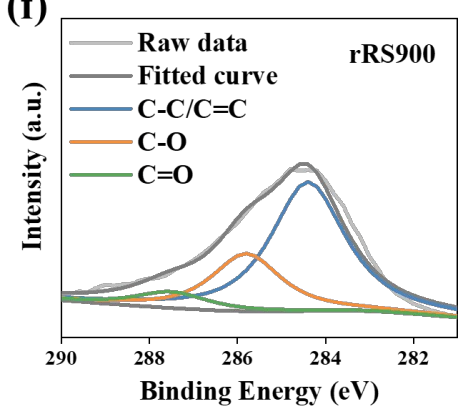

Figure S17. (a) XPS spectra and (b f) C 1s XPS spectra of PC rRS500-rRS900. C 1s XPS spectra was deconvoluted into three peaks at $284.6 \mathrm{eV}$ for $\mathrm{C}-\mathrm{C} / \mathrm{C}=\mathrm{C}$, at $286.0 \mathrm{eV}$ for $\mathrm{C}-\mathrm{O}$, and at $287.8 \mathrm{eV}$ for $\mathrm{C}=\mathrm{O}$. 
(a)

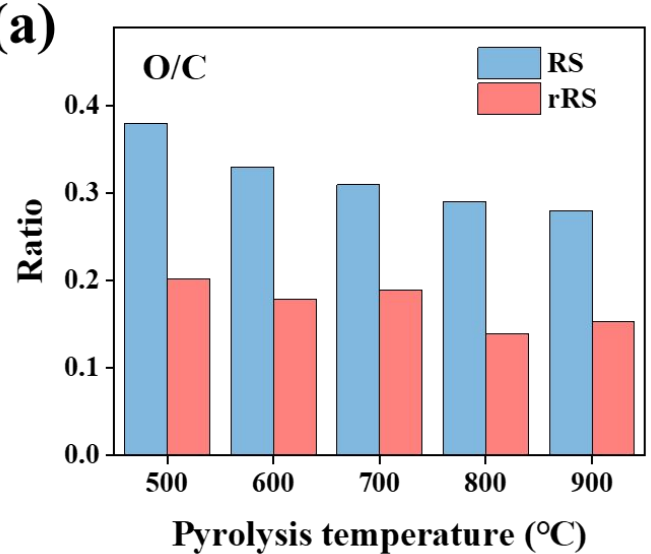

(c)

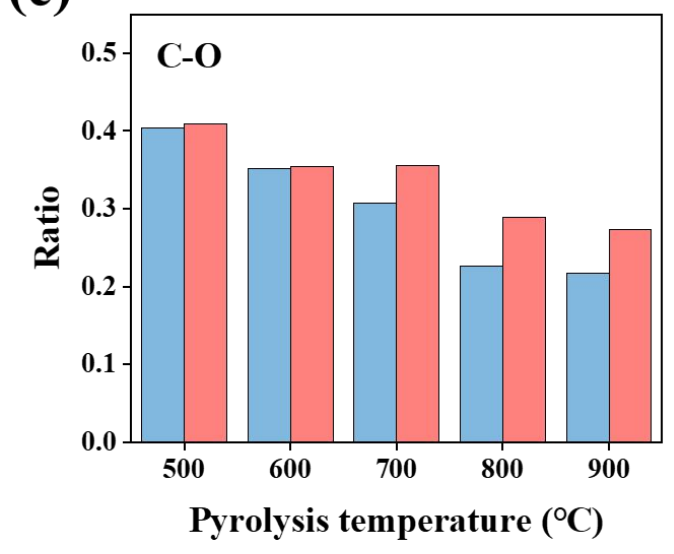

(b)

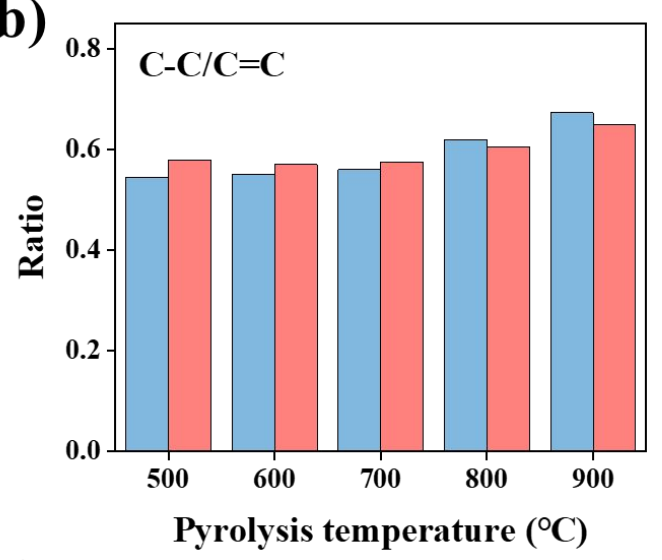

(d)

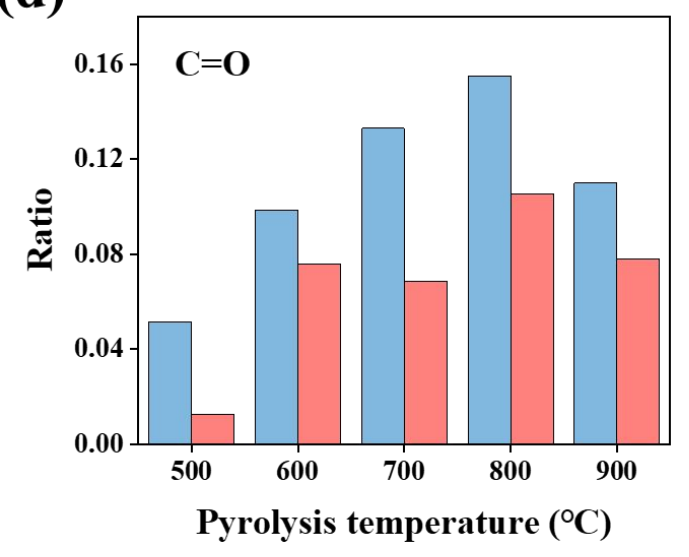

Figure S18. Comparison of (a) $\mathrm{O} / \mathrm{C}$ ratio, (b) $\mathrm{C}-\mathrm{C} / \mathrm{C}=\mathrm{C}$, (c) $\mathrm{C}-\mathrm{O}$, and (d) $\mathrm{C}=\mathrm{O}$ bands between PC RS500-RS900 and rRS500-rRS900. 

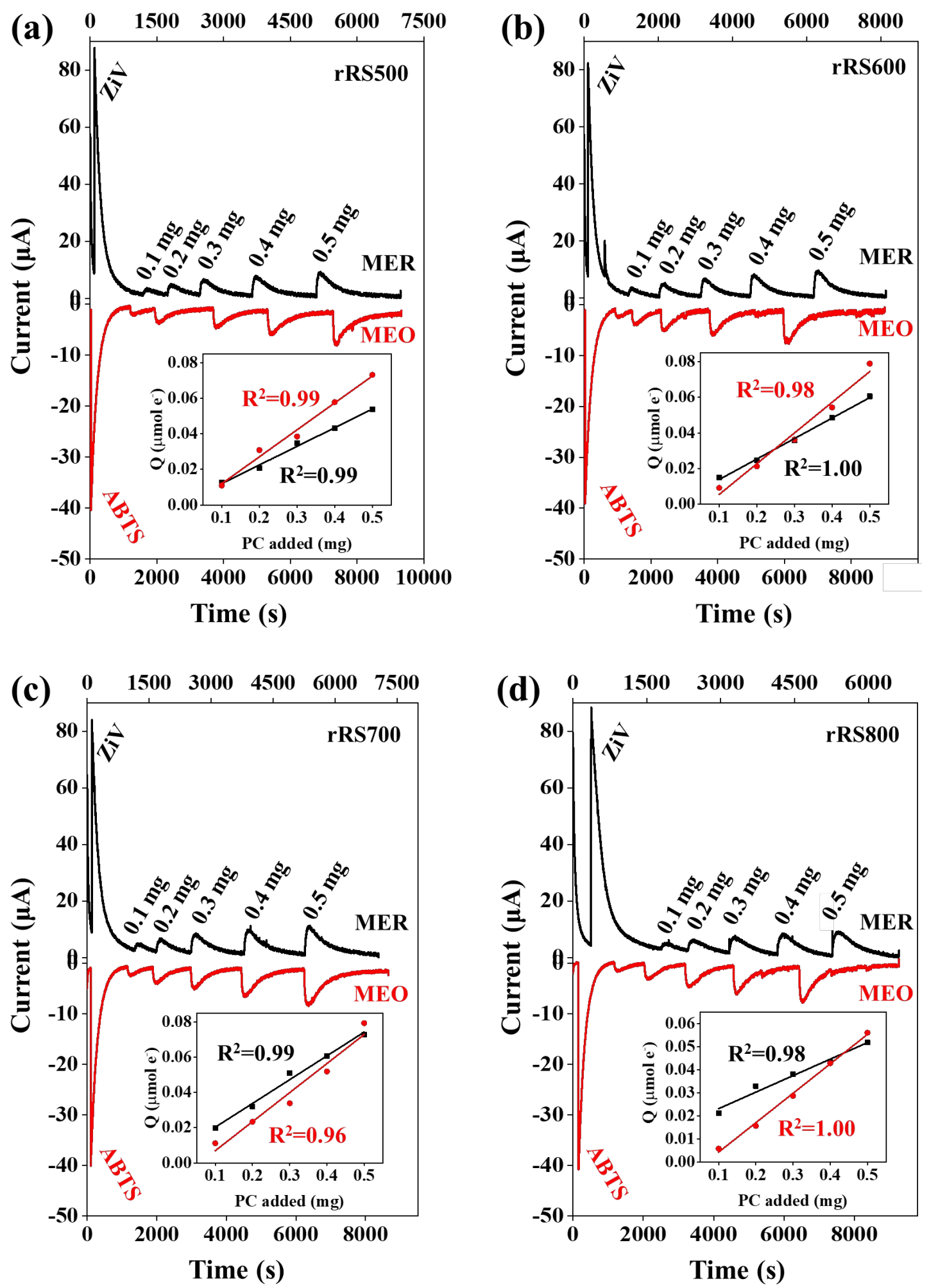


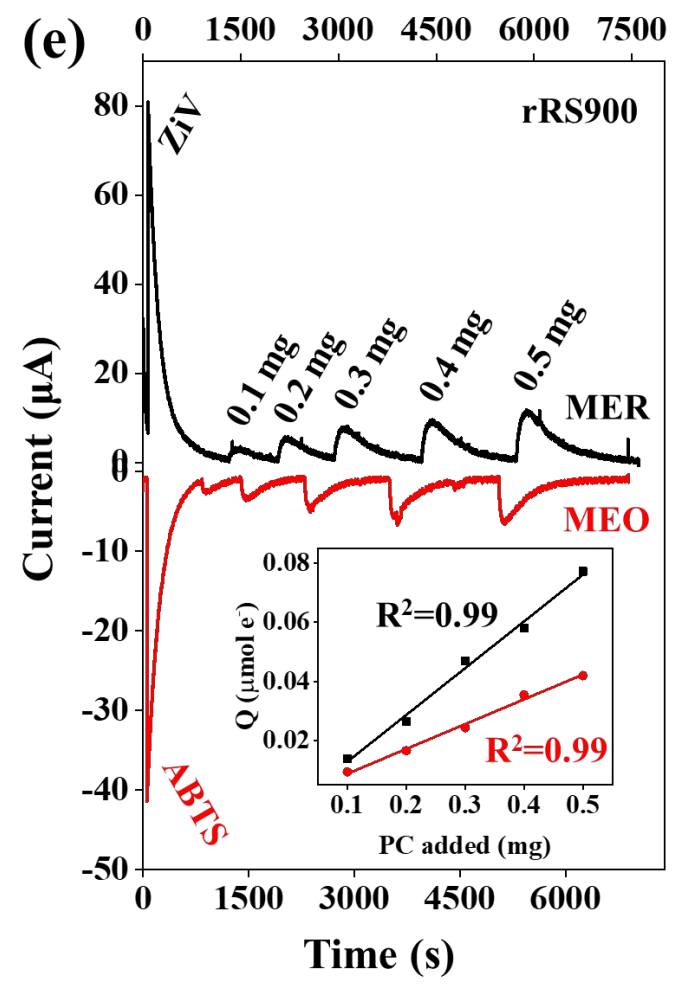

Figure S19. (a e) Reductive and oxidative current responses to increasing amounts of PC rRS500-rRS900 measured by mediated electrochemical reduction (MER; $E_{\mathrm{h}}=-0.49$ $\mathrm{V}, \mathrm{pH} 7.0$; black traces) and mediated electrochemical oxidation (MEO; $E_{\mathrm{h}}=+0.61 \mathrm{~V}$, pH 7.0; red traces), respectively. The numbers above the current peaks represent the mass of PC added into the cell. Integration of the current peaks yielded the numbers of electrons transferred to and from the PC, Q ( $\mu$ mol e-). Q increased linearly with increasing masses of PC (inserts). The slopes of linear regression lines of Q versus PC masses corresponded to the electron accepting and donating capacities of PC (EAC and EDC). 


\section{REFERENCE}

(1) Gorski, C. A.; Klüpfel, L. E.; Voegelin, A.; Sander, M.; Hofstetter, T. B. Redox properties of structural Fe in clay minerals: 3 . relationships between smectite redox and structural properties. Environ. Sci. Technol. 2013, 47, (23), 13477-13485.

(2) Wu, S.; Fang, G.; Wang, Y.; Zheng, Y.; Wang, C.; Zhao, F.; Jaisi, D. P.; Zhou, D. Redoxactive oxygen-containing functional rroups in activated carbon facilitate microbial reduction of ferrihydrite. Environ. Sci. Technol. 2017, 51, (17), 9709-9717.

(3) Dong, Y.; Sanford, R. A.; Boyanov, M. I.; Flynn, T. M.; O’Loughlin, E. J.; Kemner, K. M.; George, S.; Fouke, K. E.; Li, S.; Huang, D.; Li, S.; Fouke, B. W. Controls on iron reduction and biomineralization over broad environmental conditions as suggested by the firmicutes Orenia metallireducens strain Z6. Environ. Sci. Technol. 2020, 54, (16), 10128-10140. 